\title{
A Surgical Audit to Determine Whether Size of Patent Ductus Arteriosus Can Be A Factor to Decide the Modality of Surgical Treatment
}

\author{
Dr.Dwarkanath Kulkarni ${ }^{1}$, Dr.Kamlesh Jain ${ }^{2}$, \\ Dr. Vishal Pingle ${ }^{3}$, Dr. Sundeep $\mathrm{S}^{4}$ \\ ${ }^{I}$ (Department Of CVTS , KEM Hospital \& Seth G.S.Medical College, Mumbai, India) \\ ${ }^{2}$ (Department Of CVTS, KEM Hospital \& Seth G.S.Medical College, Mumbai, India) \\ ${ }^{3}$ (Department Of CVTS, KEM Hospital \& Seth G.S.Medical College, Mumbai, India) \\ ${ }^{4}$ (Department Of CVTS, KEM Hospital \& Seth G.S.Medical College, Mumbai, India)
}

\begin{abstract}
The Patent Ductus Arteriosus (PDA) is one of the commonest acynotic congenital heart disease. Most of these can be managed by device closure. But very large, long or very short PDA are prone for failure. Simple ligation of PDA has been shown to have high recurrence rate. We in our institute categorized PDA depending on the size of PDA at the pulmonary end.Accordingly, the operative procedure was determined either direct ligation or by modified division and suturing tehnique. Keywords: calcific PDA, Patent ductus arteriosus, large PDA, division and suturing of PDA
\end{abstract}

\section{Introduction}

Patent Ductus Arteriosus( PDA ) is one of the commonest acyanotic congenital heart disease. The first definitive description of PDA was done by Guillo Cesare Aranzio of Bologna. He discovered the ductus arteriosus of fetus in a postmortem dissection. In 1904, Willims introduce the idea of spontaneous delayed closure of the ductus. John Munro in 1907 floated the idea of ligation of the PDA. On $6^{\text {th }}$ March 1937 the first attempt of PDA closure was done by John Strieder of Boston. It was a case of infective endocarditis. Patient died on third postoperative day. This was published a year later in American heart journal. (1,) In 1939 , Robert Gross of Boston was first to successfully close the ductus arteriosus . In 1943 Touroff was first to divide the PDA. However, it was not intentional, but was accidental while achieving hemostasis. $(3,4)$ In 1944 , Gross demonstrated that 14 patients treated with ligation had recanalization. $(5,6,7)$ Johns in 1947 demonstrated that there was no recurrence with division and suturing .(2) With the advent of catheter based non invasive procedures the device closure of PDA has become a gold standard. But still many PDAs which are very large, long or are very short, hypertensive ductus or ductus in premature require surgical closure. In our institute 4 cases with very large PDA ( $>$ than $5 \mathrm{~mm}$ ) showed recurrence over a period of 3 years. Hence, in very large ductus ( $>$ than $5 \mathrm{~mm}$ ) we started using division and suturing technique. Other small ductus are closed by double ligation. Hence, we divided the cases depending on the size of the PDA. Diameter of $5 \mathrm{~mm}$ was chosen as the differentiating factor. Other cases under went double ligation by polyester suture (2-0)

\section{Operative Technique}

1) Patient in right lateral position.

2) Posterolateral thoracotomy and the fourth interspace is entered by detaching the intercostal muscle from the superior rib margin and sharply incising the parietal pleura.

3) The ribs are retracted, and two malleable retractors are used to retract the left upper lobe and the superior segment of the left lower lobe

4) With the take-off of the left subclavian artery used for orientation, the parietal pleura is openedand fixed with interrupted sutures

5) Pleural retraction sutures are used to expose the duct.

6) The crossing vein is divided when it obscures dissection of the upper duct angle.

7) The upper and lower angles are dissected, with care being taken to avoid cautery near the left recurrent laryngeal nerve as it sweeps under the duct.

8) The posterior margin is freed with a blunt right-angle clamp.

9) Bring down the systolic blood pressure to about $90 \mathrm{mmHg}$.

10) Large ducts are clamped proximally and distally with Cooley's clamps taking sufficient bites of posterior wall of aorta.

11) Clamp on pulmonary artery is put avoiding the recurrent laryngeal nerve. 
12) The anterior wall of the ductus is incised first and then the posterior wall keeping more wall on aortic side.

13) The duct is then divided; each end is over sewn with running prolene suture (5-0) taking good bites of posterior wall.

14) Clamps are removed one after another and gauze pieces are kept pressed if there is some bleeding from needle holes which usually stops.

15) Hemostasis is achieved. And the parietal pleura is closed. And the drain is inserted.

16) Patient is extubated in early postoperative period.

17) In one case of hypertensive ductus in whom the needle holes started bleeding due to hypoplastic aorta and the clamps had to be reapplied on aortic end sutures on felt was taken.

18) This method is also used in calcified ductus.

\section{Important points that were observed during the operation are :}

1) Hypotension upto $90 \mathrm{mmHg}$ with the help of anaesthetic agents.

2) Careful dissection of aorta

3) Cooley clamps were applied to get secure control of both ends of the ductus and thus there was no danger of the clamp slipping.

4) It allows unhurried and very careful closure of ductus both at pulmonary and aortic ends.

5) Even hypertensive ductus and calcified ductus could be safely divided by using this technique

6) Blood transfusion was required only in 1 cases of hypertensive ductus.

7) There was no operative mortality in this series.

\section{Follow-up:}

Points observed during followup are:

1) All the hypertensive cases were totally symptom free.

2) There is marked decrease in the heart size

3) Decrease in pulmonary congestion

4) No delayed complications were found in all the cases

5) Soft systolic murmur was heard in 2 patients who had severe pulmonary hypertension

\section{Results}

We performed 10 cases with division and suturing technique over a period of 3 years from 2012 to 2015. All of them were with isolated large PDA ( > than $5 \mathrm{~mm}$ ). 12 patients with small PDA (< $5 \mathrm{~mm}$ ) underwent direct ligation. $30 \%$ of the patients were females. The ages ranged from 12 days to 14 months. The youngest weighed 650 grams. There were no immediate or late postoperative deaths. There were no intra-operative or post-operative complications. The mean hospital stay was 3 days. Repeat ECHO on follow-up did not show recanalization in either group.

\section{Discussion}

Patent Ductus Arteriosus (PDA) is one of the commonest acyanotic congenital heart disease. Ligation of PDA is widely practiced but is associated with chances of recanalization. Pérez-Redondo and Limón confirmed that division of PDA was the optimal surgical management.( 8) After PDA ligation, $19.7 \%$ of patients presented either recanalization or incomplete closure. (10) Aneurysm of PDA is among the complications of surgical PDA ligation. (11) In some cases, false aneurysm occurred after recanalization of PDA.(10,12) Even with double or triple ligation, 22\% of patients had residual PDA and required division of PDA. Ductal recanalization occurs in 6 to $23 \%$ of patients, to perform PDA division instead of PDA ligation is advised.(13) Open division represents the gold standard, with almost 50 years of experience to support this technique. Direct anatomic control and visualization minimize the risk of hemorrhage, and ductal division eliminates concern about residual ductal patency.

We, in our study found that the size of PDA at the pulmonary end plays an important factor that determined the chances of recanalization. We arbitrary decided upon $5 \mathrm{~mm}$ at the pulmonary end as the cut off point to decide the surgical modality.

We did not find any difficulty in dividing and suturing even the premature ductus.

\section{Conclusion}

PDA division and suturing appears to be the safest, most effective and widely applicative therapeutic procedure for PDA larger than $5 \mathrm{~mm}$ at the pulmonary end. For smaller PDA double ligation is safe and effective. However, larger, long follow up and a multicentric study is required to set up a definitive guideline.. (10) 


\section{References}

[1]. Division, or ligation of patent ductus arteriosus? Alberto Rangel,* Héctor Pérez-Redondo,** Javier Farell, Marcelo Noé Basave, Carlos Zamora. Volumen 13, Número 4 Octubre - Diciembre 2002 pp $158-161$

[2]. John C. Johns : 25 years experience of surgery of PDA . Journal of Thoracic and Cardiovascular surgery . 50: 149, 1965

[3]. Touroff, A. S. W. (1942). A modified technique of surgical ligation of patent ductus arteriosus. Surgery, 12, 24-30.

[4]. Ambalavanan SK, Mehta AV. Correspondence to the editor (Letter). J Pediatr Surg 1997; $32: 661$.

[5]. Gross RE. Surgical management of patent ductus arteriosus with summary of four surgical treated cases. Ann Surg 1939; 110 : 321.

[6]. Gross RE. Complete surgical division of the patent ductus arteriosus: a report of fourteen successful cases. Surg Gynecol Obstet 1944; $78: 36$.

[7]. Gross RE. Complete division of patent ductus arteriosus. J Thorac Surg 1947; 16: 314

[8]. Pérez-Redondo H, Limón-Lason R, Pérez-Muñoz R, Salgado EJL. Tratamiento quirúrgico de la persistencia del conducto arterioso con muy severa hipertensión pulmonar (casos llamados inoperables o de muy alta mortalidad). Única serie en México de 13 enfermos operados sin mortalidad. Cir Ciruj 1970; 37: 129-135.

[9]. Quijano-Pitman F, Velasco De la Cruz P, García CM, González QJ. 170 cases of patent ductus arteriosus operated consecutively without mortality. Arch Inst Cardiol Mex 1968; 38: 878-881.

[10]. Jones JV. Twenty-five years experience with surgery of patent ductus arteriosus. J Thorac Cardiovasc Surg 1965; 50: 149-165.

[11]. Lund JT, Jensen MB, Hjelms E. Aneurysm of the ductus arteriosus. Eur J Cardiovasc Surg 1991; 5: 566-570.

[12]. Ross RS, Feder FP, Spencer FC. Aneurysms of the previously ligated patent ductus arteriosus. Circulation 1961; 23: 350-355.

[13]. Podnar T, Matsura J. Transcatheter occlusion of residual patent ductus arteriosus after surgical ligation. Pediatric Cardiol 1999; 20: 126-130. 